\title{
The Application of the STM to English Teaching in Primary School $^{*}$
}

\author{
BAI Jin-Xin, MENG Fan-Mao \\ Linyi University, Linyi, China
}

\begin{abstract}
The Situational Teaching Methodology (STM) is a neoteric and effective teaching method, which aims to create situations to arouse the students' interest of learning. In the process of English teaching, the STM emphasizes on the real situation of language learning, and facilitates students' listening and speaking skills by creating situations. It can create the vivid scene during teaching to help students understand the teaching materials in the textbooks. In primary-school English teaching, it is vital to use the proper method to teach pupils to learn English according to their characters.
\end{abstract}

Keywords: the STM, English teaching, pupils’ interest of learning

\section{Introduction}

The Situational Teaching Methodology (STM) is original called Oral Approach, and it is developed by British applied linguists from 1930s (Shu, 2000). The concept of the STM is first projected by Brown, Collin, and Duguidin in 1989 (Lu, 2013). Palmer and Hornby are the main advocators of the STM (Shu, 2000).

There are different kinds of expressions on the STM. According to Gu Mingyuan (1998, p. 364), "The STM is a kind of method through the use of the vivid scene, to arouse the students' interest of learning, to improve learning efficiency". Zhang Hua (2000, p. 478) believes that "The STM refers to create the problems with real event or circumstance. Students are in the process of solving the incidents or problems, and understand the knowledge independently”. As for Lu Yaqiong,

the STM means a lively or concrete situation or scene the teacher establishes with the emotional color by the body of image, in order to draw the students' attitude experience, to help the students understand the textbook, and also improve the students' mentality development. The center of the STM is to motivate the students' emotion, making them learn actively and happily. (2013, p. 3)

As far as I'm concerned, the so-called STM primarily refers to the concept that it includes the guidance of the syllabus and teaching materials, and in the meantime, from the cognitive aspect to teach language with the structural elements and the functions to create all kinds of situations to make the students immerse in a rich, the environment of natural or semi-natural speaking. It holds the aim to make the students contact, input, and absorb

\footnotetext{
* Acknowledgements: This article is sponsored by the program "A Study on the University Students Engaging in WeChat Business and Their Academic Records".

BAI Jin-Xin, student, School of Foreign Languages, Linyi University, Linyi, China.

MENG Fan-Mao, M.A., professor, School of Foreign Languages, Linyi University, Linyi, China.
} 
much more language materials in the natural or man-made scenes. With similar discourse pattern to express their cognition of the society or an object, to show their innermost feelings, and by the expression with other students, they can establish a cognitive or emotional contact, and finally solidify their mastery of the discourse patterns.

In brief, the STM is a kind of teaching method that stimulates students' learning interests with some vivid situations. It aims to create a kind of social environment which conveys the message in English and focuses on the created scenes or contexts. Moreover, the method guides the students to have a direct contact with the English-spoken countries' culture atmosphere. In fact, the STM regards the scene establishment as the breakthrough point, and cultivates the primary-school students' communicative skills as the purpose. In the light of the features of the pupils and based on their present knowledge level and ability, the STM aims to develop the pupils' initiative, awareness, imagination, and creativity during the process of learning English. The sense organs of the learners will be affected by the scenes and it will make pupils have the motivation and intention to communicate with others. Psychologists indicate that students' learning motivation and their thirst for knowledge cannot appear naturally, unless they depend on the teaching scenes which teachers set up. Therefore, teachers must frequently set up kinds of scenes for students consciously. For the reason that most of Chinese pupils are lack of English language learning atmosphere, it is inevitable to create scenes for their English learning. Learn English under such scenes. Only in this way can the students get better learning effects.

\section{The Theoretical Basis of the STM}

The theory of the STM is mainly influenced by linguistic structuralism. The principle of the interaction between emotional and cognitive activities is the first theoretical basis. The aim of STM is to stimulate students' positive and healthy emotional experience in teaching procedure, and enhance the students' enthusiasm in studying directly, and so as to make sure that the students can carry out the learning activity willingly and pleasantly. The emotions enhance the efficiency of cognitive activities, and from these activities we gain new education on solving the problems that so far the primary students have motive power. Emotional adjusting function refers to the concept that the emotions have the function to organize or disintegrate cognitive activities, that is to say, the appropriate and kind mood is beneficial to the organization and process of bright works. And students could study in more comfortable and merry learning atmosphere. Therefore, the STM is better than traditional teaching and it can obviously accomplish better teaching effects.

Next theoretical basis goes to the intuitive principle of cognition. With the STM, the students lie in the particular environment and it will show them lively and concrete images including direct and indirect ones. In this way, the students can accomplish the choice of abstract and reasonable cognition from visual image from one thing; and from another thing, it stimulates students' studying interests, making the students absorbed in their learning and get better results.

The last one is the similar principle of thinking sciences. The principle is similar to the theory of generalization and the theoretical basis of STM. Image is the subject of context. The similar context in situational teaching should involve the imagination of model essay and teaching requirements as objects. And they also ought to be consistent with students' knowledge and experience. In the teaching process, the STM often brings about a large number of distinct scenes, i.e., it can provide a lot objects that are perceptive to the students to make their knowledge units grow in quantity, which helps the students arouse afflatus and improve the ability to think in the similar way. 


\section{The Ways of Creating the Situations}

When the teacher delivers an English lesson, creating certain situations is mainly teacher-oriented according to the students' development level. Generally speaking, the situations can be created in the following ways.

\section{To Describe the Situation by Language}

To describe the language in the situation is the most basic and important way. As the unique tool of teachers' creating teaching situation, it is a method that has been the most commonly used. With the situational teaching process, the teacher is available to use some simple words to describe brilliantly. Hence, the teacher will lead the pupils come into the required situations.

Language is an effective way when it comes to the STM. What's important is that when an English class comes, it is vital for the teachers to use English to complete his class. As usual, pupils are often in the Chinese language environment, no matter listening, speaking, reading, and writing. In fact, only English classroom is the suitable condition for students to practice English. If the teachers teach the pupils with Chinese in English class, it is useless for the pupils to improve their English. Thus, the teacher should try their best to teach in English in the class. When encountering some more difficult words, phrases, or sentences, the teacher should also try to use simple English words to express and explain. Sometimes it may be hard for the pupils to comprehend the internal meaning, and under the present circumstance, he should also prefer to use the pictures or actions to explain. To create a strong English atmosphere can accomplish that the pupils can use English to think throughout the whole process. To communicate in English is more difficult to be replaced by other ways of real language speaking situations. The teacher should start with English from his first lesson and do not accommodate the students. As time goes by, the students will gradually form the habit of using the situations to understand English.

\section{To Represent the Situation With the Pictures}

Pictures are often intuitive and vivid. Using pictures is another magic key to lead the pupils' imaginable thinking. To some extent, it is the extending of the material objects in actual life. According to the pupils' psychological characteristics, the pupils' attention can be easier to focus on the targeted things. Using pictures, models, slides, videos, TV, and other teaching equipment, the teacher can freely create different teaching situations in the classroom on the basis of the STM. The teacher visualizes the text content and vocabulary. The visualization can arouse the interests of the pupils and trigger the pupils' imagination. For example, the teacher can set up some pictures and ask the pupils according to the different content production of slide in the text. Naturally, the pupils can better understand the plot. Then the teacher guides the students to learn listening and speaking, the pupils can fully understand the meaning of the story, and can tell the whole story with the new learned words and sentence structures. Through the slides and drawing in English class teaching, it will leave a deep impression on what they have learned.

For some abstract nouns or difficult to find equivalence objects or difficult to take into the classroom, the teacher can use the images such as stick-figure and prospects to show. For instance, with the vivid pictures on the blackboard, a few pen stick-figures can move the park into the classroom. The pupils can speak their bosom freely: Today I will go to the park. I want to see the flowers, the grass, and the trees. I enjoy playing with my friends in the park. When we refers to this scene, it seems that the pupils are really experiencing this situation. They image that they are in the park and play in the park with their friends. By associating with the situation, they 
are easy to imagine and they are willing to speak out their inner minds. No wonder, the better class teaching effect appears. Apart from the pictures, using charts matching with the textbooks in teaching is also an effective way. After the text, the students retell the story according to the charts, and look at the language materials and. Wall charts bring them into the situation of the text and they are easy to be brought into the situation and can express their idea naturally. Later on, the students' ability of language expression can be improved significantly. Another example: as for learning the lesson about giving direction, pictures do have the great importance. The students draw some pictures according to the dialogues. When the students finish learning the text, they can get a brief knowledge of the useful sentence patterns.

In the following process, the teacher shows the pictures about the directions. The pupils use the new sentence patterns to make dialogues. In this process, the teacher can ask some basic questions about the directions to check out the pupils' learning effect. In the following link, the roles exchange. The pupils can be the teachers. They ask each other's questions according to the pictures. In the end, the teacher makes a summary.

\section{To Show the Situation With the Objects}

While pupils are much younger, and lack of experience and knowledge, they are good at thinking in imagination. Objects usually possess the character of visualization and imagination which are popular among the pupils. Under the condition that the teacher just teaches the students with boring theoretical knowledge, the students are bound to divert their attention from what the teacher is teaching. Using some specific objects to teach can clearly establish the direct connection with the words, phrases, or sentences and its concept. It is beneficial for the pupils to train them to think in English thought and avoid unnecessary translations. This kind of communication with objects is more closed to the communication activities in actual life. At the same time, it will make the students' language abilities and communication skills improve. What's more, primary-school students are active, curious and have strong imitation ability. They are easy to accept the specific content. However, their self-control is weak and they are easy to disperse the attention. If the teacher adopts the STM, it can cause their strong interest in learning English and attract their attention. In addition, they can connect the lively image with abstract thinking. Therefore, it can deepen their understanding and memorize what they have learned.

For instance, learning a lesson about the fruit, the teacher can apply the method. When study the sentence patterns such as "What are you favorite fruits? Do you like...?”, The teacher can bring the objects of various kinds of fruits, drinks, and colored paperboards into the classroom. The teacher can make use of these objects to develop his class teaching. The colorful objects can quickly catch the pupils' eyes and they will have high interest and enthusiasm.

\section{To Show the Situation Through the Role Playing}

Role playing is a term of social psychology. It is a kind of social psychology art that makes people in other people's social position temporarily. The teacher aims to promote people the understanding of its original role and others' roles and the students learn to better perform their roles. In order to make the students deeply experience into the role of the situation, the role play should be introduced into English classroom teaching. What's more, it also makes the students absorbed in the environment of the application of English and learns to use English. Because we just learn English mainly in class and the pupils often lack of the environment to apply English. Therefore, we combined with the text as much as possible in class to provide a variety of circumstances 
to make the students have the opportunity to practice. Role playing and performance to study English is effective. It not only increases the students' attention but also enhances the interest of learning. What's more, it also can mobilize the students' thinking and active the classroom atmosphere. Thus, we can make the students learn in a more relaxed situation. Then the students can skillfully grasp of the learning content. Eventually, the students can enhance the ability of using English in communication.

Role-playing in the primary-school English teaching can be divided into two parts: the mechanical and the developmental. The former refers to the primary-school students perform according to the text content, for example, role-play reading and performance. Such activities make the teaching situations reappear. The pupils can grasp the quick perception of the teaching material content and easily understand the teaching content. In the story, the things seem to be done by the pupils themselves, and the words seem to be said by themselves. If the pupils can perform in a real way, they can be in a much more relaxed way to master the knowledge. The developmental role playing refers to the creative performance to active the thinking and enriches the imagination based on the textbook and combines with the content in daily life and makes use of the sentence patterns they have learned before, so as to guide the students to come into their life and make the students create the situations. By using the role playing, the students can consolidate the learned knowledge and cultivate their ability.

For instance, the teacher teaches the present continuous tense. The first step is that the teacher asks a student to answer the questions. In the meantime, the teacher asks the other students to answer what the student is doing. The students can quickly understand the abstract concept of the present continuous tense in this situation. In the meantime, the teacher guides the students to say he is answering the questions. The teacher asks two representative students to perform such situation. In this situation, one student role-plays as the teacher, and the other one is still the student. Through the performance, they transform the abstract concept by the live demonstration into the concrete language.

\section{To Teach Through Lively Games}

Games can not only satisfy the students' loving dynamic nature, which in turn creates a pleasant earning atmosphere. In addition, the process of English game itself is the reuse of knowledge. It can recreate a large number of learned knowledge, help students to consolidate the learned knowledge, and enhance the memory, so that the students can both accomplish learning and playing. According to the present age, the students' psychological characteristics, and the requirements of the teaching material content, the teacher can design all kinds of games to create teaching situations. In this way, the students are exposed to various kinds of colorful games. When cooperating with partners, the students can easily master knowledge and form ability in the process of imitating practice and application. Game teaching can be separated into two aspects, including testing and training. The training games aim to encourage the students to open the mouth to practice. It can not only stimulate students' interest in learning, but also make students in a relaxed and lively atmosphere in language learning and master the language skills. Apart from those advantages, it also can activate the thinking ability of the students and cultivate the students' self-confidence. The testing fames are mainly to check the students' listening and speaking skills. The testing game is used to examine the teaching effect. It is an effective way to correct the pronunciation, consolidate the vocabulary, and practice the oral language skills. 
The students are willing to play games. When playing games, they can be in a higher mood and fully show their intelligence. For instance, learn the lesson about the animals in the zoo. The teacher can ask the students to play a game. At first, the representative students are divided into two groups. Choose two students to act as narrators. They can read the story in the textbook. The remaining students can act as the animals and the visitors. While the narrators make the storytelling, the others play the games. If the students can play the game correctly, the teacher can award them. On the contrary, the students should get the punishment. For instance, they can sing songs for the whole class. This class is both tense and live. In the idyllic atmosphere, the students can not only consolidate the knowledge, but also further familiarize the words (Jing, 2008). In fact, when the students are in high spirits, they can easily remember the knowledge. What's more, the teacher can design some games, such as hide-and-seek, word-guessing games, and crossword games and so on. It can effectively prevent students from fatigue and boredom, fully arouse the students' enthusiasm, and effectively enhance teaching effect.

\section{To Render the Situation Through the Music}

Children's instincts lie in like singing and jumping. The pupils like rhythmic and catchy songs. Beautiful music and the expressive dialogues can change the static and abstract words into a dynamic and specific language communication situation. Students are exposed to an atmosphere of beautiful melody and harmony and come into the palace of the knowledge of English, and then appreciate the pleasure of learning. English nursery rhythms and songs can not only benefit to the pupils' learning English pronunciation and strengthen the grammar and vocabulary ability, but also make the pupils learn English in a relaxed way. What's more, it also lets the pupils laid a good foundation of English unconsciously. A song before class can not only create a positive learning English atmosphere, but also attract the attention of students and force them into the English class. In addition, it also can activate the students' knowledge reserves and it evolves the old knowledge into the new knowledge. Three to five minutes earlier before the class, the teacher plays harmonious and beautiful classic English songs or the students' familiar music. On the one hand, it can make the students quiet and relax their psychology; on the other hand, the class can be organized effectively and the new lesson can be led naturally. The songs can both be used at the beginning and the class or applied in the middle of the class. The teachers can also apply some familiar songs to the new sentences, in order that the students can learn new knowledge in the happy and relaxed atmosphere and form the better learning habit.

If we use the music in the middle of the class, it can increase the students' learning interests and make them relaxed. During the teaching process, students' emotion and learning motivation may decrease due to nervous rhythm of learning, and to some extent it will bore their energy. By now, a beautiful song or nursery rhythm appears. Next they can learn the lesson in a relaxed way. No doubt, it will achieve half the work with double results. In this way, the teachers can use the song to teach the learning content in primary-school, which is beneficial to stimulate students' interest and scatter the difficult points. Thus, putting the music in English teaching can improve the students' understanding of dialogues and situations. In this way, the students can blend in the vivid language situations. For example, the pupils learn some new words and phrases about the festivals. The teacher can compile a new song based on the nursery rhythm "little star". The students are immersed in the song's beautiful melody. Exposed to such a pleasant situation, the students can learn the new words merrily and quickly. 
On condition that the music can be used at the end of the class, it can summarize the text and remain the learning interests. The students finish the task in the music and even long for more about the knowledge. By singing, the students can easily find their mistakes and rectify their pronunciation. Students will consciously eliminate the interference of objective factors during singing and enhance the attention to the language. In addition, they can adjust their plan according to their learning procedure and complete the language they have learned. When the teacher converts the relevant sentence patterns students have learned and the words that are often pronounced mistakenly into the songs, the students' attention will be attracted by the melodious songs. Thus, such troubles can be resolved step by step. The pupils sing the songs with the melody in a relaxed way and they are affected by the infinite charm of English culture, with the aim to strengthen the studied knowledge.

\section{Conclusion}

In conclusion, the STM can create a certain environment of learning English in which the students can study and use English in an effective way. Therefore, the STM can be applied in the English teaching in primary-school. There exist a large number of teaching methods. However, from my perspective and perception, the STM is much better than the others, especially when we refer to the English teaching in primary-school.

The experiential teaching methodology can not only make the students be the master of study, but also can obtain the abilities of optimum learning. The primary-school English teaching adopting the STM will lead to a sharp improvement in the quality of English teaching. Teachers should be based on the teaching content to create real language environment, so as to help the students to better accomplish cognition, understand and memorize the learned knowledge, and apply the knowledge into practice. By presenting the real scenes, teachers can guide the students with the aim that it can make students apply the knowledge they have learned into their daily lives. As we all know, pupils can get great benefit from the STM. This paper is aimed at accomplishing the goal to make the students learn English effective and have the willing to learn English. The STM is indeed a useful way to teach the primary-school students. In spite of its some drawbacks to some extent, the outstanding English teachers are expected to reasonably apply this method and find the key to successful English teaching. All in all, in primary-school English teaching, the STM should be taken into consideration.

\section{References}

Gu, M. Y. (1998). Education dictionary. Shanghai: Shanghai Education Press.

Jing, A. H. (2008). Creating situations and cultivating students' creative personality. China Education Innovation, 4, 156.

Lu, Y. Q. (2013). Situational teaching method in primary school English teaching (A thesis for Bachelor of Arts, Xi'an International Studies University).

Shu, D. F. (2000). Problems and strategies for reforming foreign language teaching. In Proceedings of the Chinese Academy of Pragmatics, 8, 14-21.

Zhang, H. (2000). Curriculum and Teaching Methodology. Shanghai: Shanghai Education Press. 